\title{
Program Kemitraan Masyarakat Universitas Widyagama Malang pada Usaha Peningkatan Industri Rumah Tangga Keripik Tempe Pemula
}

\author{
Gigih Priyandoko ${ }^{1}$, Faqih $^{2}$, Agus Tugas Sujianto ${ }^{3}$ \\ 1,2 Jurusan Teknik Elektro, ${ }^{3}$ Jurusan Teknik Sipil, Fakultas Teknik \\ 1,2,3 Univeritas Widyagama- Jalan Borobudur No. 35 Malang 65142 \\ *e-mail corresponding author : gigih@widyagama.ac.id
}

\begin{abstract}
ABSTRAK
Tempe merupakan salah satu makanan khas Indonesia yang sudah lama dikenal. Di berbagai daerah di Indonesia, banyak sekali jenis olahan makanan berbahan dasar kedelai. Walau bagaimanapun terdapat berbagai kendala dalam melaksanakan bisnis kripik tempe bagi pemula. Tujuan yang akan dicapai dalam program kali ini adalah pertama, mencari pisau untuk memotong tempe dengan hasil yang lebih tipis, sehingga menghasilkan jumlah irisan kripik yang lebih banyak dan lebih renyah. Kedua, perlunya mendesain ulang kemasan bungkus kripik tempe yang lebih menarik para pembeli. Ketiga, pemberian merk yang lebih spesifik untuk memudahkan pembeli mengingat produk dan yang keempat perlunya menghasilkan berbagai varian rasa kripik tempe dengan untuk menjangkau pembeli yang lebih luas. Penilaian keberhasilan pelaksanaan program pengabdian masyarakat ini dilakukan dengan pembuatan kuisioner kepada pembeli untuk mengetahui seberapa besar efek perubahan sebelum dan setelah dilakukan beberapa tindakan oleh mitra produsen kripik tempe. Hasilnya adalah dengan membuat pisau yang lebih besar dapat menghasilkan irisan lebih tipis. Desain bungkus telah dimodifikasi dan merk dagang telah diberi nama yang jelas yaitu Aulia. Untuk varian rasa banyak pembeli memilih rasa original kripik tempe.
\end{abstract}

Kata kunci : kripik tempe; kedelai; bisnis; usaha kecil dan menengah (UKM)

\begin{abstract}
Tempe is one of Indonesia's traditional foods that has long been known. In various regions in Indonesia, there are many types of processed foods made from soybeans. However, there are various obstacles in conducting tempe chips business for beginners. The goal to be achieved in this program is first, to find a knife to cut tempe with thinner results, resulting in many slices of chips and more crispy. Second, the need to redesign the tempe chip wrapper package which is more interesting for buyers. Third, giving a more specific brand to make it easier for buyers to remember the product and the fourth is the need to produce a variety of flavours of tempe chips to reach a wider audience. The evaluation of the successful implementation of the community service program was carried out by making a questionnaire to the buyer to find out how much the tempe chip producer partners took the effect of the changes before and after some actions. The result is that making a larger knife can produce thinner slices. The packaging design has been modified and the trademark has been given a clear name, Aulia. For flavour variants, many buyers choose the original taste of tempe chips.
\end{abstract}

\section{Keywords : tempe chips; soy; business; small and medium enterprises (SMEs)}

Cara Mengutip : Priyandoko, G., Patma, T.S., Purwanti, E. (2020). Program Kemitraan Masyarakat Universitas Widyagama Malang pada Usaha Peningkatan Industri Rumah Tangga Keripik Tempe Pemula. JAST: Jurnal Aplikasi Sains dan Teknologi, 4 (1), 61-67. doi:http://dx.doi.org/10.33366/jast.v4i1.1591

\section{(c) (i) (2)}

EY SA Content from this work may be used under the terms of the Creative Commons AttributionShareAlike 4.0 International License. Any further distribution of this work must maintain attribution to the author(s) and the title of the work, journal citation and DOI. 


\section{PENDAHULUAN}

Tempe merupakan salah satu makanan khas Indonesia yang sudah dikenal sejak lama. Di berbagai daerah di Indonesia, banyak sekali jenis olahan makanan berbahan dasar kedelai. Tempe begitu lekat dengan kehidupan masyarakat sehingga tempe dijuluki sebagai makanan rakyat [1]-[4]. Cara membuat keripik tempe ini juga tergolong mudah, cukup digoreng kering dengan irisan tipis dan dicampur dengan bumbu rempah dan bahan-bahan lainnya agar terasa gurih dan nikmat. Kebanyakan orang menikmati keripik tempe ini sebagai pelengkap makan, tetapi karena keripik tempe ini masuk ke dalam kategori makanan ringan, banyak orang yang menjadikan keripik tempe ini sebagai cemilan tanpa ditemani dengan nasi dan makanan berat lainnya.

Rahasia utama dari kerenyahan yang dihasilkan oleh keripik tempe adalah teknik mengiris dan menggoreng tempe [5] - [7]. Diusahakan saat mengiris tempe jangan sampai merusak tekstur dan tempe diiris tipis secara searah, kemudian setelah diberi bumbu, dilakukan penggorengan tempen dengan kondisi minyak yang cukup banyak di wajan. Selain enak dan gurih, keripik tempe ini juga memiliki kandungan gizi yang dihasilkan dari biji kedelai sebagai bahan dasar. Keripik tempe ini juga tidak mengandung kolesterol yang tinggi jika penggorengannya benar-benar kering [1], [5], [8].

Sekarang ini sudah ada banyak produsen keripik tempe yang mulai menambahkan berbagai macam varian rasa pada keripik tempe yang diproduksi. Seperti Keripik Tempe Maicih yang memiliki varian rasa balado, barbeque, keju, pedas manis, jagung bakar, pedas level, dan masih banyak lainnya. Ini merupakan salah satu strategi pemasaran untuk bisa membuat banyak orang semakin tertarik dan menyukai keripik tempe [2], [4], [9] - [11].

Mitra pada pengabdian ini adalah pengusaha pemula kripik tempe di Dukuh Tumpangrejo, Desa Kebobang, Kecamatan Wonosari, Kabupaten Malang. Produk kripik tempe dari mitra dapat dilihat pada Gambar 1.

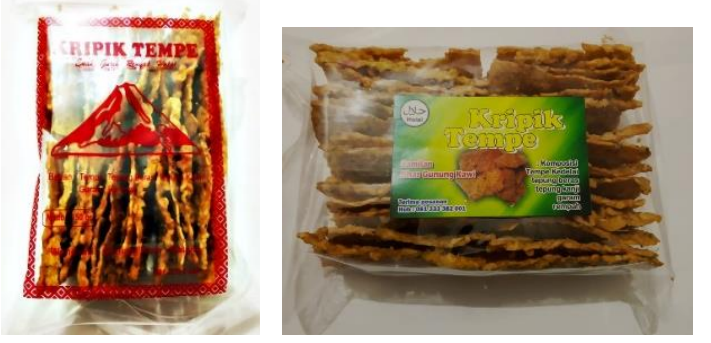

Gambar 1. Kemasan Lama.

Pada Gambar 1 dapat dilihat bahwa, kemasan dibuat dua macam dengan bahan plastik dengan rasa kripik tempe yang original. Awalnya persaingan tidak terlalu banyak, tetapi pada akhirakhir ini muncul berbagai macam merk kripik tempe dan berbagai macam varian yang dititipkan di toko-toko daerah tersebut. Karena dari pengusaha besar, harga jual dari pesaing tersebut lebih murah dan tampilan yang lebih menarik, sehingga penjualan mitra makin menurun. Permasalahan yang kedua, tidak memiliki merk yang spesifik. Ketiga, pemotongan tempe yang akan dijadikan kripik tempe kurang tipis, karena kesulitan mendapatkan pisau yang sesuai. Keempat, perlu pengemasan yang lebih menarik untuk mendapatkan pembeli yang lebih banyak. Kelima, tersaji kemasan kripik tempe dengan rasa 
yang masih konvensional. Keenam, modal yang masih kecil, sehingga belum dapat bersaing dengan pengusaha besar dalam penentuan harga jual yang lebih rendah.

Pembahasan dalam kajian ini akan difokuskan pada empat masalah saja, yaitu untuk mendapatkan irisan kripik yang tipis, diperlukan pisau khusus, untuk dihasilkan irisan yang lebih banyak dan lebih renyah. Kedua, merk dagang yang digunakan adalah "kripik tempe", jelas hal ini kurang menarik minat pembeli dan kurang baik dari segi pemasaran. Ketiga, desain ulang kemasan biar lebih menarik, dan yang keempat adalah varian rasa yang akan dilakukan 4 rasa yaitu original, jagung manis dan bbq, balado dan rasa bbq.

\section{METODE KEGIATAN}

Langkah pertama yang dilakukan adalah diskusi dengan mitra tentang alat, desain kemasan yang akan dipakai dan dibuat sesuai skala prioritas yang akan diselesaikan pada program pengabdian ini. Diskusi dipertajam dengan referensi yang mendukung agar peralatan yang didesain dan dibuat mempunyai keandalan yang baik. Solusi yang ditawarkan untuk menyelesaikan permasalahan mitra di atas adalah mencakup:

a. Mencari pisau yang sesuai untuk dapat memotong tempe yang lebih tipis.

b. Pemberian merk sebagai tanda yang mudah untuk mengingat.

c. Mendesain beberapa alternatif kemasan bungkus kripik tempe yang lebih menarik. d. Membuat berbagai varian rasa kripik tempe.

Untuk mendapatkan bagaimana respon dari pelanggan akan dilakukan kuisioner sebelum dan sesudah dilakukan upayaupaya beberapa perubahan di atas.

\section{KARYA UTAMA}

Pada bagian ini akan diterangkan setiap langkah yang dilakukan dalam mengatasi empat permasalah di atas secara satu persatu. Langkah pertama yang dilakukan adalah diskusi dengan mitra tentang alat, desain kemasan yang akan dipakai dan dibuat sesuai skala prioritas yang akan diselesaikan pada program pengabdian ini.

Pada bagian ini penulis menguraikan teknik atau cara menyelesaikan tantangan, persoalan atau kebutuhan pokok yang menjadi target kegiatan atau kesepakatan bersama. Dapat dipilih salah satu metode atau kombinasi dua atau beberapa metode berikut ini.

- Pisau

Berdasarkan pengalaman yang diperoleh mitra, hasil irisan tempe dengan menggunakan pisau lama agak tebal dan kurang tipis (Gambar 2a). Sehingga dalam produksinya kurang menghasilkan irisan yang banyak, dan kerenyahan kripik terasa kurang yang disebabkan irisan tempe yang terasa masih tebal. Untuk mengatasi hal tersebut, menghubungi pandai besi untuk mendapatkan pisau yang tajam dan dapat dengan mudah untuk melakukan pemotongan tempe dengan hasil yang tipis. Hasil pembuatan pisau yang baru oleh pandai besi dapat dilihat pada Gambar 2b. Mitra merasakan perubahan penggunaan 
pisau yang baru tersebut. Pemotongan tempe terasa lebih mudah karena pisau yang tajam dan bobot pisau yang agak berat. Irisan tempe yang dihasilkan lebih banyak, karena ketebalan irisan yang tipis-tipis.

\section{o Merk Dagang}

Kemasan dan merk dagang harus dilakukan perubahan. Karena merk yang digunakan sebelum ini terasa kurang menarik, yaitu "Kripik Tempe". Merk dagang tersebut menyulitkan pembeli yang akan membeli lagi atau menyarankan teman lain untuk membeli produk tersebut, karena merk dagang yang tidak spesifik. Terjadi diskusi dalam menentukan nama merk dagang. Nama yang di pilih akhirnya adalah "Aulia”.

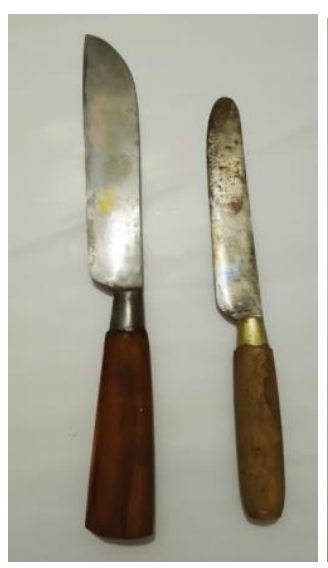

(a)

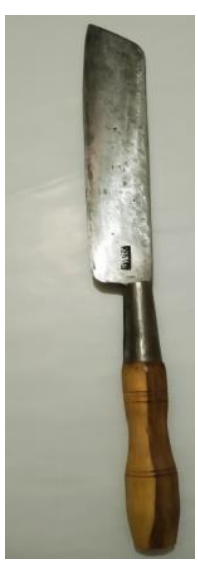

(b)
Gambar 2. Pisau (a) lama (b) baru

\section{- Desain Kemasan}

Perubahan stiker dan kemasan dilakukan pembuatan beberapa stiker yang baru. Stiker dengan merk dagang yang baru telah dibuat sebanyak 5 desain stiker seperti pada Gambar 3. Desain kemasan yang telah dipakai tetap dimasukkan dalam survei ini dengan memberi label stiker 1 .
Dalam upaya mendapatkan masukan positif dari pelanggan, dilakukan survei terhadap 26 orang, dan hasil pemilihan stiker tersebut adalah sebagai berikut:

Pemilih stiker 1: 0 reponden

Pemilih stiker 2: 1 reponden

Pemilih stiker 3: 1 reponden

Pemilih stiker 4: 5 reponden

Pemilih stiker 5: 19 reponden

Sehingga berdasarkan survei tersebut, dipilih stiker pada Gambar 3e dipilih untuk tampilan kemasan yang baru. Pemakaian kemasan yang baru yang tampak lebih menarik dan mudah diingat oleh pembeli untuk menyarankan teman lain untuk membeli juga lebih mudah, dengan menyebut merk dagang yang telah digunakan seperti yang ditampilkan pada Gambar 4.

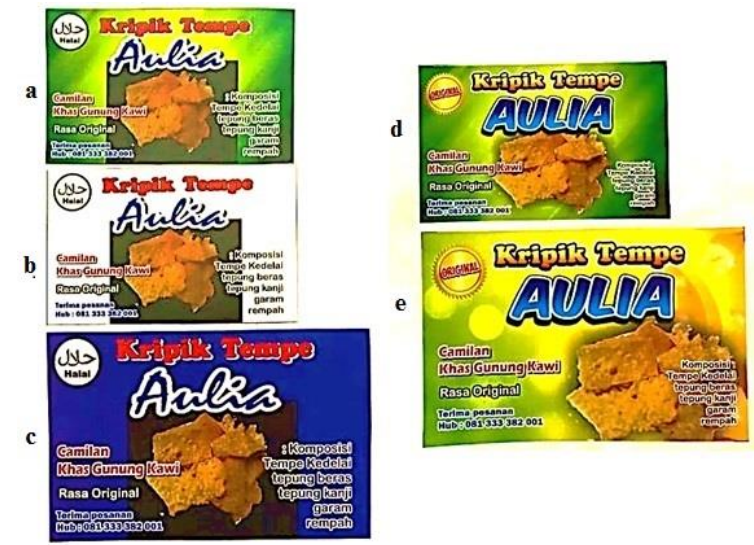

Gambar 3. Desain stiker kemasan dan merk dagang

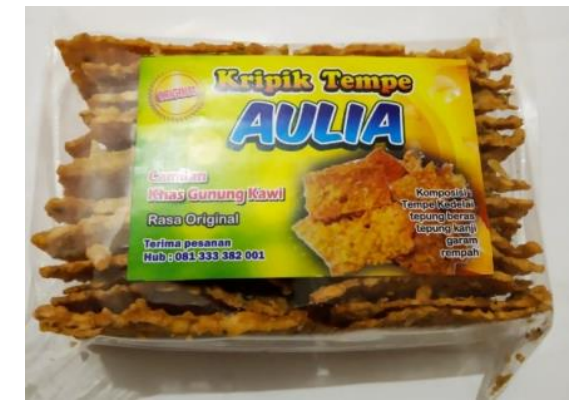

Gambar 4. Kemasan baru 


\section{- Varian Rasa}

Selama ini varian rasa yang telah diproduksi oleh mitra adalah rasa original. Belum adanya varian rasa yang dibuat. Sehingga disarankan untuk membuat beberapa alternative varian rasa, yaitu rasa jagung manis, rasa bbq, dan rasa pedas balado. Setelah dilakukan penggorengan kripik tempe di wajan pada Gambar 5.

Kripik tempe yang sudah digoreng harus ditiriskan terlebih dahulu untuk memisahkan kripik tempe dan minyak goreng. Penirisan dilakukan dengan serok manual seperti pada Gambar 6.

Kripik tempe yang telah kering bebas dari minyak goreng diletakkan di atas meja untuk diberi berbagai macam rasa. Meja tersebut diberi alas koran agar varian rasa yang ditaburkan dapat rata pada kripik tempe.

Berdasarkan hasil survei yang telah diadakan oleh mitra tentang varian rasa yag telah diuji coba, hasilnya untuk masing-masing rasa dengan jumlah peminatnya adalah sebagai berikut:

a. Varian rasa original : 16 orang

b. Varian rasa jagung manis : 5 orang

c. Varian rasa bbq : 6 orang

d. Varian rasa balado : 7 orang

e. Dari hasil survei di pelanggan di sekitar rumah mitra dapat dilihat bahwa kebanyakan pembeli lebih cenderung memmilih rasa original. Sehingga mitra untuk sementara konsentrasi untuk memproduksi kripik tempe dengan rasa original. Tetapi untuk pengembangan usaha, varian rasa akan dilakukan percobaan lebih mendalam untuk mendapatkan resep yang lebih enak untuk menarik pembeli.

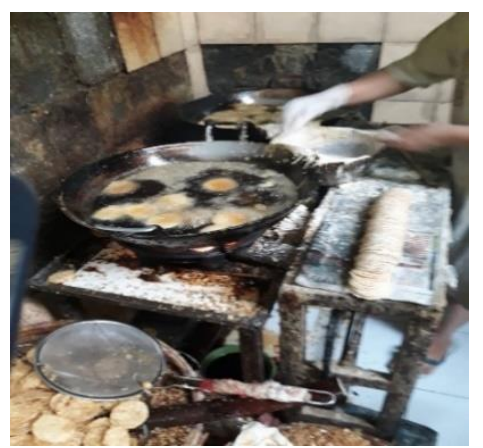

Gambar 5. Penggorengan kripik tempe

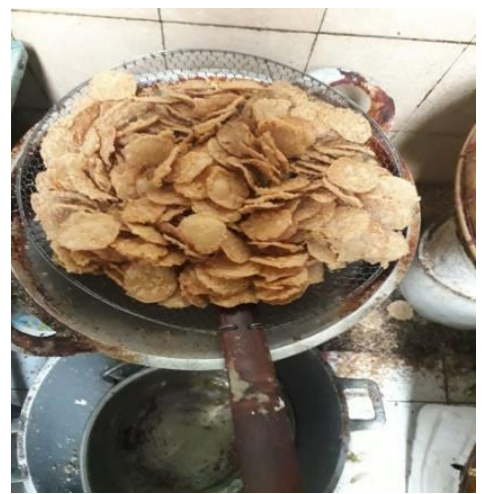

Gambar 6. Penirisan kripik tempe

\section{DAMPAK DAN MANFAAT KEGIATAN}

Dampak dan manfaat dari kegiatan pengabdian masyarakat untuk pengusaha pemula ini diamati setelah dua bulan adalah mitra pengusaha kripik tempe merasakan semakin banyak mendapatkan produksi kripik tempe, karena alat pengiris tempe yang lebih nyaman digunakan dan menghasilkan irisan yang lebih tipis dan lebih banyak irisan dengan bahan baku yang relatif sama. Karena irisan yang lebih tipis, menghasilkan kripik yang lebih renyah.

Selain itu dengan pemberian merk dagang Aulia lebih memudahkan pembeli untuk mengingat, dan efeknya selama dua bulan menunjukkan jumlah penjualan 
yang cenderung meningkat meskipun masih dengan nilai persentase yang kecil.

Desain kemasan yang lebih menarik menjadikan pembeli lebih tertarik untuk memilihnya dari berbagai kripik tempe yang tersedia di etalase toko.

Membuat berbagai varian rasa kripik tempe sudah dilakukan, tetapi untuk sementara tetap mengandalkan rasa kripik tempe yang original sebagai andalan. Tetapi untuk varian rasa yang lain tetap menjadi perhatian mitra dengan melakukan beberapa kali percobaan untuk mendapatkan resep yang terbaik. Selain itu melakukan kunjungan ke produsen kripik tempe yang telah besar untuk mendapatkan masukan tentang varian rasa yang lebih banyak dan lebih enak.

\section{KESIMPULAN}

Dengan mencari pisau yang sesuai dapat menghasilkan irisan tempe yang lebih tipis sehingga menghasilkan kripik tempe yang lebih renyah dan lebih banyak. Pemberian merk yang lebih spesifik memudahkan pembeli mudah mengingat. Mendesain kemasan yang mencolok dan menarik sehingga menjadikan lebih mudah dipilih pembeli. Varian rasa ternyata belum diperlukan untuk jenis keripik tempe ini, karena kebanyakan responden masih memilih rasa original. Rekomendasi kegiatan pengabdian kepada masyarakat selanjutnya adalah menyelesaikan masalah pembukuan dan pemasaran produk agar mitra dapat bergerak dari pedagang pemula berubah lebih besar lagi.

\section{PENGHARGAAN}

Ucapan terima kasih diberikan kepada pihak-pihak yang paling berperan dalam membantu kelancaran kegiatan Program Pengabdian Masyarakat yang telah didanai sepenuhnya oleh Universitas Widyagama, Malang. Ucapan terima kasih juga disampaikan kepada Mitra Kerja kripik tempe Aulia.

\section{DAFTAR PUSTAKA}

[1] Vandro, "Mau Usaha Rumahan? Ini Dia Resep Keripik Tempe Renyah dan Gurih - Distributor Pusat Jual Beli Alat Mesin Usaha Anda," 2019. https://www.rumahmesin.com/resepkeripik-tempe/ (accessed Nov. 23, 2019).

[2] A. Z. Siregar, "Aneka Keripik Tempe Bergizi dan Tepat Guna Mendukung Kedaulatan Pangan," p. 9, 2018.

[3] D. R. Rahadi and E. Susilowaty, "Kreatifitas Kewirausaan Sosial dan Menggali Ide Usaha Baru Melalui Pengolahan Kripik Tempe Lupin," vol. 1, no. 1, p. 8 .

[4] A. Andayani and S. Hambali, "Poduksi Tempe Sebagai Wirausaha Mahasiswa Santri," Dimas J. Pemikir. Agama Untuk Pemberdaya., vol. 17, no. 2, p. 327, Apr. 2018, doi: 10.21580/dms.2017.172.2432.

[5] Rusaidah, "Keripik Tempe Aneka Rasa yang Pasti Laku Dijual dan Sukses Bikin Keluarga Ketagihan Bangka Pos,” 2019. https://bangka.tribunnews.com/2019/ 02/20/keripik-tempe-aneka-rasa- 
yang-pasti-laku-dijual-dan-sukses-

bikin-keluarga-ketagihan (accessed Nov. 23, 2019).

[6] F. Suryanti and K. A. Mediaswati, "Usaha Kecil dan Menengah Keripik Tempe di Kecamatan Blimbing Kota Malang Untuk Peningkatan Pendapatan Usaha," JAST J. Apl. Sains Dan Teknol., vol. 1, no. 1, Mar. 2017, doi: 10.33366/jast.v1i1.717.

[7] S. Bali, "Pengembangan Usaha Industri Rumah Tangga Keripik Tempe Di Tabanan,”p. 5, 2019.

[8] A. Maulana, "Cara Membuat Keripik Tempe dan Peluang Usahanya yang Menjanjikan | Ramesia Mesin Indonesia," 2019. https://ramesia.com/cara-membuatkeripik/ (accessed Nov. 23, 2019).

[9] W. Wiyaka, F. Reffiane, and F. Cahyadi, "Pemberdayaan Industri Rumah Tangga sebagai Upaya Peningkatan Pendapatan Tambahan Kelompok Keluarga Mitra Program Terpadu Pemberdayaan Masyarakat Berperspektif Gender Desa Langse Kecamatan Margorejo Kabupaten Pati Tahun 2016," E-DIMAS, vol. 8, no. 2, p. 191, Sep. 2017, doi: 10.26877/e-dimas.v8i2.1653.

[10] W. Suryandani and A. A. Mahmudi, "Pengembangan Kualitas SDM dan Usaha Kelompok Pengrajin Tempe Desa Tahunan Kecamatan Sale Kabupaten Rembang," vol. 1, p. 9, 2018.

[11] T. Kurniawati, N. Sa'ida, W. Wahono, and P. Hermoyo, "Peningkatan Produktivitas
Pengusaha Tempe," Aksiologiya J. Pengabdi. Kpd. Masy., vol. 2, no. 2, p. 181, Mar. 2019, doi: 10.30651/aks.v2i2.2406. 